\title{
A study of endophytic fungi Neofusicoccum ribis from Gandaria (Bouea macrophylla Griffith) as enzyme inhibitor, antibacterial, and antioxidant
}

\author{
Trisanti Anindyawati ${ }^{*}$, Praptiwi $^{2}$
}

${ }^{1}$ Bioprocess Division, Research Center for Biotechnology, ${ }^{2}$ Botany Division, Research Center for Biology, Indonesian Institute of Sciences, Jl. Raya Bogor Km.46, Cibinong 16911, Indonesia

\section{ARTICLE INFO}

Article history:

Received on: March 26, 2018

Accepted on: April 25, 2018

Available online: January 20, 2019

Key words:

Endophytic fungi,

Neofusicoccum ribis,

Enzyme inhibitor,

Antibacterial,

Antioxidant

\section{ABSTRACT}

This study aims to evaluate the potential of endophytic fungi isolated from Gandaria (Bouea macrophylla Griffith) as sources of enzyme inhibitor, antibacterial, and antioxidant and identify the chemical compounds of active extract. The endophytic fungi were identified as fungi closely related to the genus Neofusicoccum ribis based on sequence analysis of the $28 \mathrm{~S}$ rDNA and internal transcribed spacer region. $N$. ribis was cultured on potato dextrose broth and extracted with hexane, ethyl acetate, and partition between methanol and ethyl acetate, respectively. Bioactivity screenings as enzyme inhibitor (acetylcholinesterase/acetylcholinesterase inhibitor (AChE) and $\beta$-glucosidase), antibacterial, and antioxidant were conducted by thin-layer chromatography-bioautography method. The chemical compounds were analyzed by gas chromatography-mass spectrometry (GC-MS). The results showed that the ethyl acetate extract of $N$. ribis had the activity as enzyme inhibitor for $\mathrm{AChE}$ and $\beta$-glucosidase. The minimum inhibitory concentration values of $N$. ribis extract against Staphylococcus aureus and Escherichia coli were in the range of $512->512 \mu \mathrm{g} / \mathrm{mL}$. Hexane extract had better antioxidant activity $\left(\mathrm{IC}_{50}=479.66 \mu \mathrm{g} / \mathrm{mL}\right)$ than ethyl acetate extract $\left(\mathrm{IC}_{50}=928.09-1102.60 \mu \mathrm{g} / \mathrm{mL}\right)$. The GC-MS analysis showed that 12 identified chemical compounds were found in the ethyl acetate extract of $N$. ribis.

\section{INTRODUCTION}

Plant has been known as a host of several endophytic fungi. The endophytic fungi defined as microorganisms that grow inside the plant without causing any harm to the host plant and they are living in a mutualistic symbiosis with their host [1,2]. Although the relationship between endophytes and their host differs each organism, endophytic fungi are an important component of microbial biodiversity [3]. Many endophytic fungi have the same or similar bioactive component because they live together with host plants for long period of time [4]. Some of endophytes may be producing bioactive substances that may have a relationship with host plant such as specific endophytes that produce taxol as an anticancer drug isolated from Taxus brevifolia [5]. They are also known to be producers of bioactive compounds. A number of interesting biological activities of endophytic

\footnotetext{
*Corresponding Author

Trisanti Anindyawati,

Research Center for Biotechnology,

Indonesian Institute of Sciences,

Jl. Raya Bogor Km. 46,

Cibinong 16911, Indonesia.

Phone: +62-21-875-4587,

Fax: $+62-21-875-4588$.

Email:atrisanti@yahoo.com
}

fungi, i.e., antioxidant, anticancer, immunomodulatory, antiviral, antitubercular, antiparasitic, and insecticidal activities [6], and a number of substances produced by endophytic fungi had been used in medicine, agriculture, and industry $[7,8]$.

Bouea macrophylla Griffith or locally known as Gandaria in Indonesia is a tropical fruit plant from Southeast Asia. In Indonesia, it is distributed in North Sumatra, Java, Kalimantan, and Ambon. This plant belongs to the family of Anacardiaceae [9]. Gandaria fruit has significant amounts of nutrients and can be explored for the commercial purpose [10]. Methanolic extract of unripe fruits has high phenolics content, tannins and ascorbic acid, flavonoids, and flavonols in the ethanolic extract. The unripe fruits of B. macrophylla showed the highest antioxidant activity [11].

In this study, we reported the bioactivity of $N$. ribis extract isolated from Gandaria as sources of enzyme inhibitor, antimicrobial, and antioxidant and to identify the bioactive compounds of active extract by gas chromatography-mass spectrometry (GC-MS).

\section{METHODS}

\subsection{Isolation and Identification of Endophytic Microbes}

Fresh and healthy Gandaria plant was collected from Bogor Botanic Gardens, Indonesian Institute of Sciences in 2009. The healthy 
twigs showing no disease symptoms were cut $1 \mathrm{~cm}$ length and washed under running tap water for $10 \mathrm{~min}$. The surface of twigs was sterilized by soaking in $75 \% \mathrm{v} / \mathrm{v}$ ethanol for $1 \mathrm{~min}, 5.3 \% \mathrm{v} / \mathrm{v}$ sodium hypochlorite solution for $5 \mathrm{~min}$, and then $75 \% \mathrm{v} / \mathrm{v}$ ethanol for $30 \mathrm{~s}$, after that it was washed with sterilizes water [12]. The sterilized twigs were dried on sterilized tissue towel before cutting longitudinally into two equal parts. Inside part of twigs was placed on sterilized medium of cornmeal malt extract agar supplemented with $50 \mathrm{mg} / \mathrm{L}$ chloramphenicol to suppress bacteria growth. The inside part of the twigs contacted with the surface of the agar media. All of the samples were incubated at $27^{\circ} \mathrm{C}$ for $2-3$ weeks, and hyphae growing out from the twigs were cultured on potato dextrose agar (PDA). This was done several times to obtain pure isolate of endophytic fungi. The observation of fungi that growing up was carried out based on the color and surface. One of the pure endophytic fungi that excellent growth has been identified by Indonesian Culture Collection (InaCC) based on 28s rDNA (D1/D2 region) and internal transcribed spacer (ITS) rDNA. Primers used for polymerase chain reaction (PCR) amplification were NL-1 5'GCA TAT CAA TAA GCG GAG GAAAAG-3' and NL-4 5'-GGT CCG TGT TTC AAG ACG-3' for 28S rDNA (D1/D2 region), meanwhile ITS 4 5'-TCC GCT TAT TGA TAT GC-3' and ITS 5 5'-GGA AGT AAA AGT CGT AAC AAG G-3' for ITS rDNA. PCR products were purified by polyethylene glycol precipitation method [13]. Sequence reading was done using a built-in software in the DNA sequencer (ABI PRISM 3130 Genetic Analyzer) (Applied Biosystems). Raw sequence trimming and editing were done using Mega 4 and BioEdit. Homology study was done by BLAST, using the Fasta-formatted query sequence. Phylogenetic tree construction and analyses were accomplished using Clustal X and NJ Plot.

\subsection{Fermentation and Extraction}

The pure isolate of endophytic fungus with excellent growth was cultured on PDA medium for 1 week. After that, approximately three small pieces of endophytic fungus $\left(1 \times 1 \mathrm{~cm}^{2}\right)$ were transferred to $200 \mathrm{~mL}$ of potato dextrose broth in three of a $1000 \mathrm{~mL}$ Erlenmeyer flask. The fermentation process was done using shaking incubator for 12 days with a speed of $120 \mathrm{rpm}$. The duration of fermentation is reflected the stationary phase of the $N$. ribis. After fermentation completed, the biomass and media were centrifuged at $8000 \mathrm{rpm}$ for $20 \mathrm{~min}$ to get the supernatant. The extraction process was done according to the modified method of Kumala et al. [14]. The supernatant from one Erlenmeyer was extracted with hexane (1:1), collected, and concentrated with a rotary evaporator (a). The supernatant from the second Erlenmeyer was extracted with ethyl acetate (1:1) (b), and the third Erlenmeyer was extracted with methanol (1:1) followed by partitioned with ethyl acetate (1:1) (c). Agitation process was done for $2 \mathrm{~h}$ with a speed of $120 \mathrm{rpm}$, then separated using a separating funnel, and allowed to stand some time until there was a complete separation. This process is performed 3 times. The extract was stored at $4{ }^{\circ} \mathrm{C}$ until further analysis.

\subsection{Acetylcholinesterase Inhibitor (AChE)}

Five hundred units of AChE (Sigma) was dissolved in $500 \mathrm{~mL}$ Trishydrochloric acid buffer $(0.05 \mathrm{~mol} / \mathrm{L}, \mathrm{pH} 7.8)$ and then added with $500 \mathrm{mg}$ bovine serum albumin to stabilize the enzyme. Naphthyl acetate $(150 \mathrm{mg})$ was dissolved in $40 \mathrm{~mL}$ ethanol and then diluted with $60 \mathrm{~mL}$ of distilled water. $50 \mathrm{mg}$ of Fast Blue B salt was dissolved in $100 \mathrm{~mL}$ distilled water. $10 \mu \mathrm{L}$ of sample were transferred onto silica gel thin-layer chromatography (TLC) plate. After the plate was absolutely dried, the plate was sprayed with 1-naphthyl acetate and blown with cold wind. When the plate dried, the plate was sprayed with enzyme solution, dried, and put on closed vessel or Petri dish with wet cotton to keep the humidity and incubate for $20 \mathrm{~min}$ at $37^{\circ} \mathrm{C}$. After incubation period, the plate was sprayed with Fast Blue B solution. The extract showed AChE inhibitory activity would appear white, while inactive extract appears purple. The active compounds in extract were separated with mobile phase dichloromethane: methanol (10:1), and then, the same procedure was applied to the plate. The white bands indicated the active compounds as AChE inhibitor [15].

\section{4. $\beta$-Glucosidase Inhibitor}

A 1000 units of $\beta$-D-glucosidase (sigma) was dissolved in $100 \mathrm{~mL}$ of buffer solution. Buffer solution was made by $10.25 \mathrm{~g}$ of sodium acetate in $250 \mathrm{~mL}$ distilled water; the $\mathrm{pH}$ was adjusted to 7.5 by adding acetic acid $0.1 \mathrm{M}$. The stock solution was kept at $4^{\circ} \mathrm{C} .10 \mu \mathrm{L}$ of sample was transferred on to TLC plate and blown with cold wind then sprayed with enzyme solution. Plate was placed in closed Petri dish where the humidity was kept by putting wet cotton. The plate was incubated for $20 \mathrm{~min}$ at $37^{\circ} \mathrm{C}$. After incubation period was completed, the plate was sprayed with a mixture of naphthyl-glucopyranoside solution and Fast Blue B salt solution (1:4) to give a purple background. The active extract indicated by change color to yellow. The active compounds in the extract were separated with mobile phase dichloromethane: methanol $(10: 1)$. The $\beta$-D-glucosidase inhibitory activity was done as the same procedure. The white bands indicated the active compounds in the extract [16].

\subsection{Antibacterial Assay}

The antibacterial test was done against Staphylococcus aureus InaCC B4 and Escherichia coli InaCC B5. Bacteria were culture overnight at $37^{\circ} \mathrm{C}$ in Mueller Hinton broth (MHB). Antibacterial screening was done by autobiography method at bacterial densities of $10^{8} \mathrm{CFU} / \mathrm{mL}$. $10 \mu \mathrm{L}$ of extract $(100 \mu \mathrm{g})$ was transferred onto TLC plate (Silica gel $\mathrm{GF}_{254}$, Merck) and air-dried. The TLC plate then dipped into bacterial suspension, placed in sterile Petri dish, and incubated at $37^{\circ} \mathrm{C}$ for $18 \mathrm{~h}$. The humidity in Petri dish was kept by putting sterile wet cotton. After incubation completed, the TLC plate was sprayed with iodonitrotetrazolium p-violet (INT). The active extract which suppresses bacterial growth was shown by clear zone formation. The active compounds in extract were separated with mobile phase dichloromethane: methanol (10:1). The antibacterial assay for the developed TLC-bioautography was carried out with the same procedure. The minimum inhibitory concentration (MIC) was determined by serial dilution method in 96-well microplate in triplicate. $100 \mu \mathrm{L}$ of 2-fold MHB medium was dispensed into each well on the $1^{\text {st }}$ row. In each well, $100 \mu \mathrm{L}$ of extract $(5120 \mu \mathrm{g} / \mathrm{mL})$ in $10 \%$ dimethyl sulfoxide (DMSO) was dispensed and homogenized. Take out $100 \mu \mathrm{L}$ and put in the second row that has been fill with $100 \mu \mathrm{L}$ MHB media. This is done up to the last row. After that, $100 \mu \mathrm{L}$ bacterial suspension $\left(10^{6} \mathrm{CFU} / \mathrm{mL}\right)$ was added in each well. Streptomycin and chloramphenicol were used as positive controls, while broth medium and DMSO were used as negative controls. The microplate was incubated at $37^{\circ} \mathrm{C}$ for $18 \mathrm{~h}$. After incubation period, $10 \mu \mathrm{L}$ of INT was added into each well. Growth inhibition was determined by clear solution. MIC value was determined by the lowest concentration that shows no color change [17]. 


\subsection{Antioxidant Assay}

Antioxidant activity was determined by TLC-bioautography method. $10 \mu \mathrm{L}$ of extract $(10 \mu \mathrm{g} / \mathrm{mL})$ was transferred onto TLC plate. After air-dried, the plate was sprayed with $0.2 \%$ DPPH solution in methanol. The active extract was indicated by yellow spot with purple background after $30 \mathrm{~min}$. To know the active compounds, the TLC plate was developed with dichloromethane:methanol (10:1) as mobile phase and air -dried following $30 \mathrm{~min}$ of DPPH sprayed, the yellow bands effected which indicated the active compounds. The active extract was further analyzed for its $\mathrm{IC}_{50}$ in triplicate. $100 \mu \mathrm{L}$ of sample in a concentration of $1000 \mathrm{ppm}$ and catechin (positive control) was put in the well of $1^{\text {st }}$ row. On the $2^{\text {nd }}-8^{\text {th }}$ rows, $50 \mu \mathrm{L}$ methanol was put in the well. The samples were diluted serially by taking out $50 \mu \mathrm{L}$ of sample from the $1^{\text {st }}$ row and put in the $2^{\text {nd }}-8^{\text {th }}$ rows. After finish diluting the samples, $80 \mu \mathrm{L}$ of DPPH was added to each well and then incubated in the dark for $30 \mathrm{~min}$, and the absorbance was determined at $517 \mathrm{~nm}$ with microplate reader (varioSCAN). The scavenging capacity $(\mathrm{SC} \%)=\left[\left(\mathrm{A}_{0}-\mathrm{A}_{\mathrm{s}}\right) / \mathrm{A}_{\mathrm{o}}\right] \times 100 \%$, where $\mathrm{A}_{\mathrm{o}}$ is the absorbance of reagent blank, while $\mathrm{A}_{\mathrm{s}}$ is the absorbance of test sample. $\mathrm{IC}_{50}$ is the required concentration of the sample to scavenge $50 \% \mathrm{DPPH}$ in certain time period [18].

\subsection{GC-MS Analysis}

Chemical compounds of ethyl acetate extract were carried out using GCMS instrument (Agilent Technology GC System 6890N), equipped with capillary column HP-5MS $(0.25 \mathrm{~mm} \times 60 \mathrm{~m} \times 0.25 \mu \mathrm{m})$. The instrument was set to initial temperature $80^{\circ} \mathrm{C}$. Injector and detector temperature was $290^{\circ} \mathrm{C}$. Helium with the purity of $99.9 \%$ was used as carrier gas at a flow rate of $1 \mathrm{~mL} / \mathrm{min}$, and the volume of injected sample was $3 \mu \mathrm{L}$. The initial oven temperature was programmed at $80^{\circ} \mathrm{C}$ and increased up to $290^{\circ} \mathrm{C}$ at the rate of increase $15^{\circ} \mathrm{C} / \mathrm{min}$. The identification of the compounds was done by comparing mass spectra of the compounds with that of available mass spectral records (NIST library).

\section{RESULTS AND DISCUSSION}

\subsection{Identification and Bioactivity of Strain}

A newly isolated endophytic fungi from a twig of Gandaria plant were identified by means of PCR and DNA sequence analysis. Partial 28S rRNA (D1/D2 region) was compared with that of other plant fungi and found to be in the same cluster with $N$. ribis, Botryosphaeria ribis, and Guignardia cryptomeriae with $99 \%$ similarities. Since D1/D2 region could not differentiate $N$. ribis with $G$. cryptomeriae, further PCR amplified rDNA ITS analysis which confirms these endophytic fungi to be $99.9 \%$ identical with $N$. ribis.

Bioactivity of $N$. ribis extract was done by TLC-bioautography method. This assay is the simplest guided bioassay to discover new bioactive compounds from natural product [19]. TLC-bioautography is facilitating the localization and target-directed isolation of active compounds of extract [20]. Extract of endophytic fungi isolated from B. macrophylla was tested for its bioactivities, i.e., AChE and $\beta$-glucosidase inhibitor, antibacterial against $S$. aureus and E. coli, and also antioxidant as DPPH radical scavenger.

\subsection{TLC-Bioautography - AChE Inhibitor}

The AChE inhibitory activity of endophytic fungi extracts was done by TLC bioautography. The test relies on the cleavage by AChE of 1-naphthyl acetate to form 1-naphthol, which in turn reacts with Fast Blue B salt to give a purple-colored diazonium dye $[21,22]$.
Enzyme inhibitors block the formation of $\alpha$-naphtol and there is no purple coloration on TLC plates [22]. This method is quick in giving information about the activity and localization of active compounds in the extract [21] and rapid identification of a large number of AChE inhibitors [22]. The active chemical compounds in the extract as acetylcholinesterase inhibitor showed white spots. The extract of endophytic fungi $N$. ribis showed white spots that indicate that these compounds have AChE inhibitory activity [Figure 1].

\subsection{TLC-Bioautography - $\beta$-Glucosidase Inhibitor}

Glucosidase inhibitors are responsible for disruption of the activity of glucosidase [23] and potentially useful as antidiabetic, anti-obesity, antiviral, antiadhesive, antibacterial, or antimetastatic agents [24]. The result for TLC-bioautography of endophytic fungi $N$. ribis for $\beta$-glucosidase inhibitor is shown in Figure 2 that the extract contains compounds with $\beta$-glucosidase inhibitor activity.

\subsection{TLC-Bioautography - Antibacterial Activity}

Screening of antibacterial activity of $N$. ribis extract against $S$. aureus and E. coli is shown in Figure 3. It was indicated that extract derived

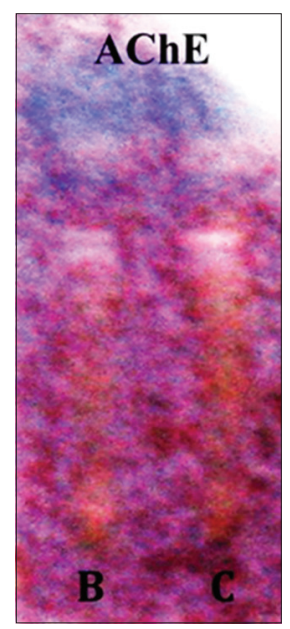

Figure 1: Thin-layer chromatography bioautography for acetylcholinesterase inhibitor (AChE). White bands indicate active compounds as AChE inhibitor

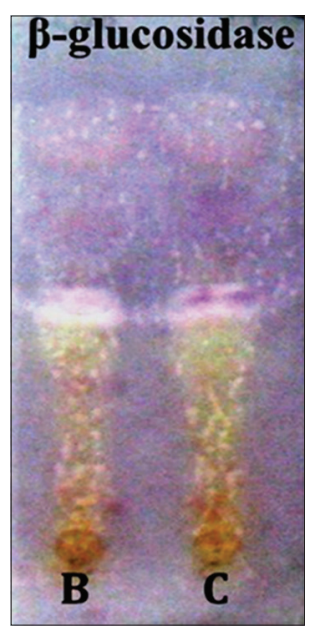

Figure 2: Thin-layer chromatography bioautography of endophytic fungi Neofusicoccum ribis for $\beta$-glucosidase inhibitor. White bands indicate the compounds as $\beta$-glucosidase inhibitor 
from methanol partitioned with ethyl acetate (C) was the most active extract against $S$. aureus compared to A and B, while extract B and C also active against $E$. coli.

The growth inhibition by the extract was indicated by clear zone formation after sprayed with INT. TLC plate as a background changes its color to purple after sprayed with INT. The purple color is caused by the conversion of INT to intensely colored formazan by the dehydrogenases enzyme of living microorganisms [25]. The interaction between viable microorganisms and INT caused a color change of INT from faint yellow to red-purple color [19]. The result of antibacterial activity showed that extracts B and C have several compounds that suppressed the growth of $S$. aureus and E. coli. The active compound that suppressed both bacteria has similar Rf value. This indicated that the compound might have a broad spectrum in suppressing bacterial growth. The results are shown in Table 1 that all of the extracts had MIC value $>512 \mu \mathrm{g} / \mathrm{mL}$ against $E$. coli and only extract $\mathrm{C}$ had the MIC value $512 \mu \mathrm{g} / \mathrm{mL}$. Extract with MIC value from 500 to $1000 \mu \mathrm{g} / \mathrm{mL}$ was considered as weak antibacterial activity [26].

\subsection{TLC-Bioautography - Antioxidant Activity}

Antioxidant activity assay used in this study was DPPH radical scavenging activity. DPPH radical scavenging assay is a quick, reliable, and reproducible for screening in vitro antioxidant of crude extract and pure compound. DPPH has the ability to donate hydrogen [19]. The antioxidant compound of extract reduced the capacity of DPPH radical by the decrease in absorbance [27]. The $\mathrm{IC}_{50}$ value of extract A was the lowest compared to extracts $\mathrm{B}$ and C. It was indicated that extract $\mathrm{A}$ had better antioxidant activity than extracts $\mathrm{B}$ and $\mathrm{C}$ [Table 2].

\subsection{Analysis of Chemical Compounds of $N$. ribis by GC-MS}

There are 12 active compounds identified by GC-MS analysis from $N$. ribis ethyl acetate extract: Undecane, cyclopentasiloxane, dodecane, 1-tetradecene, phenol, 1-hexadecene, 1-octadecene, N,N-diethyl-N',N'diphenyl-6-pyrrol-1-yl-[1,3,5] triazine-2,4-diamine, 1-docosene, N,Ndiethyl-N',N'-diphenyl-6-pyrrol-1-yl-[1,3,5]triazine-2, 4- diamine, and 1-nonadecene [Table 3]. The peak values identified in above extract are shown in Figure 4. Most of the identified compounds have been reported to possess interesting biological activities. Dodecane reported as antifungal/antibacterial [28,29]. 1-Octadecene and 1-hexadecane have been reported as antibacterial/antifungal, antioxidant, and anticancer [30]. Docosene was also reported has the ability as antifungal [31], while phenol has been reported as antioxidant, anticarcinogenic, and anti-inflammatory [32].

\section{CONCLUSION}

This study revealed that endophytic fungi of $N$. ribis ethyl acetate extract isolated from Gandaria plant contain 12 chemical compounds, some of them have biological activities. The extract contains chemical compounds with antibacterial, antioxidant, and enzyme inhibitors, especially acetylcholine esterase inhibitor and $\beta$-glucosidase inhibitor. The $N$. ribis extract against $S$. aureus and $E$. coli was in the range MIC values $512->512 \mu \mathrm{g} / \mathrm{mL}$, while hexane extract has better antioxidant activity $\left(\mathrm{IC}_{50}=479.66 \mu \mathrm{g} / \mathrm{mL}\right)$ than ethyl acetate extract $\left(\mathrm{IC}_{50}=\right.$ 928.09-1102.60 $\mu \mathrm{g} / \mathrm{mL})$. The activity as enzyme inhibitors is present
Table 1: MIC of $N$. ribis extract

\begin{tabular}{lccc} 
No & Extract & MIC $(\mu \mathrm{g} / \mathrm{ml})$ & \\
& & S. aureus & E. coli \\
1 & A & $>512$ & $>512$ \\
2 & B & $>512$ & $>512$ \\
3 & C & 512 & $>512$ \\
\hline
\end{tabular}

MIC: Minimum inhibitory concentration, N. ribis: Neofusicoccum ribis

Table 2: $\mathrm{IC}_{50}$ value of $N$. ribis extract

\begin{tabular}{lcc} 
No & Extract & IC50 $(\boldsymbol{\mu g} / \mathbf{m l})$ \\
1 & A & 479.66 \\
2 & B & 928.09 \\
3 & C & 1102.60 \\
\hline
\end{tabular}

N. ribis: Neofusicoccum ribis

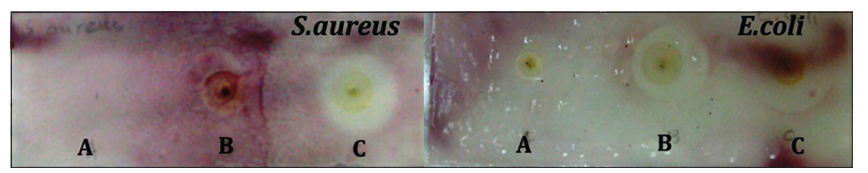

Figure 3: Thin-layer chromatography bioautography of Neofusicoccum ribis extract for antibacterial activity against Staphylococcus aureus and Escherichia coli

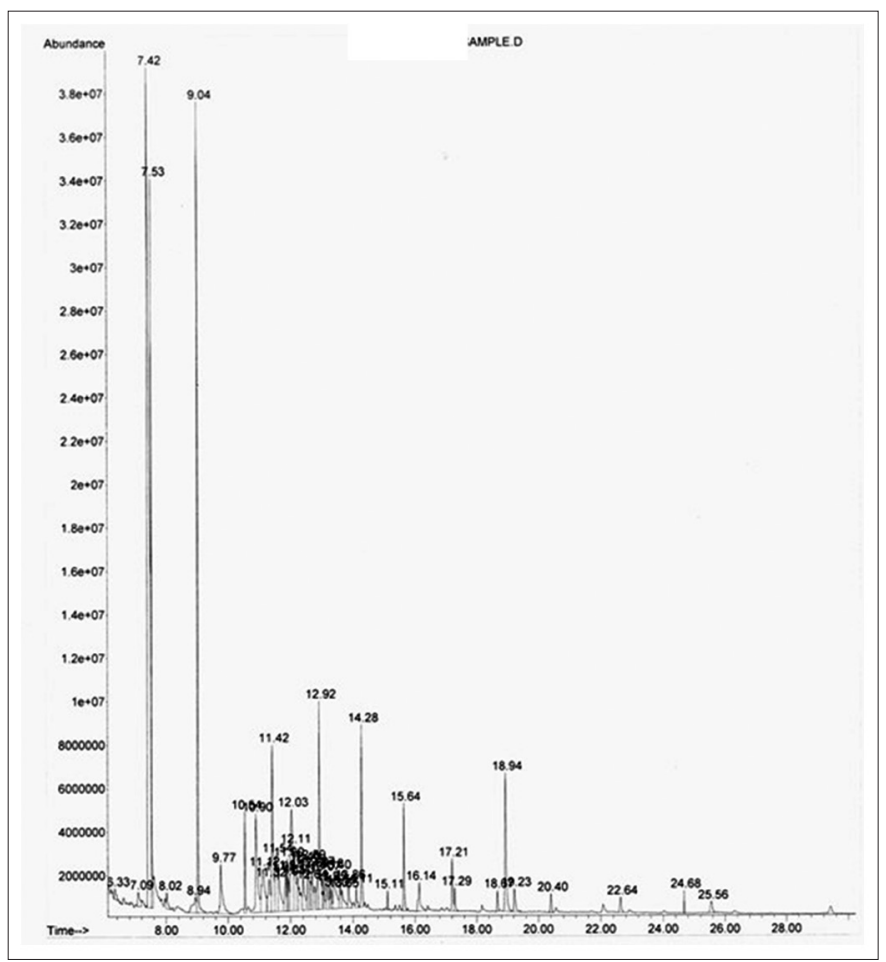

Figure 4: Gas chromatography-mass spectrometry analysis of chemical compounds

only in ethyl acetate extracts. Further, isolation and purification of bioactive compounds need to be done. 
Table 3: GC-MS Identification

\begin{tabular}{lcclc} 
No & Retention time (min) & Area $(\%)$ & Library/ ID & Quality \\
1 & 7.09 & 0.48 & Undecane & 96 \\
2 & 7.42 & 29.10 & Cyclopentasiloxane & 95 \\
3 & 8.02 & 0.43 & Dodecane & 95 \\
4 & 9.77 & 1.84 & 1 -Tetradecene & 99 \\
5 & 10.90 & 3.23 & Phenol & 95 \\
6 & 11.42 & 3.61 & 1-Hexadecene & 98 \\
7 & 12.93 & 4.14 & 1-Octadecene & 99 \\
8 & 14.28 & 2.38 & 1-Octadecene & 96 \\
9 & 15.12 & 0.21 & N, N-DIETHYL-N', N'-DIPHENYL-6-PYRRO \\
10 & 17.21 & & L-1-YL-[1,3,5]TRIAZINE-2,4-DIAMINE & 95 \\
11 & 18.67 & 0.95 & 1-Docosene & 99 \\
12 & 19.23 & 0.32 & N, N-DIETHYL-N', N'-DIPHENYL-6-PYRRO \\
\hline
\end{tabular}

GC-MS: Gas chromatography-mass spectrometry

\section{REFERENCES}

1. Petrini O, Sieber TN, Toti L, Viret O. Ecology, metabolite production, and substrate utilization in endophytic fungi. Nat Toxin 1992;1:185-96.

2. Nair DN, Padmavathy S. Impact of endophytic microorganisms on plants, environment and humans. Sci World J 2014. Article ID: 250693.

3. Khaswar RN, Misra A, Gond SK, Stierle A, Stierle D. Anticancer compounds derived from fungal endophytes: Their importance and future challenges. Nat Prod Rep 2011;28:1208-28.

4. Zhou X, Zhu H, Liu L, Lin J, Tang K. A review: Recent advances and future prospects of taxol-producing endophytic fungi. Appl Microbiol Biotechnol 2010;86:1707-17.

5. Strobel GA. Endophytes as sources of bioactive products. Microb Infect 2003a;5:535-44.

6. Hussain H, Kliche-Spory C, Al-Harrasi A, Al-Rawahi A, Abbas G, Green IR, et al. Antimicrobial constituents from three endophytic fungi. Asian Pac J Trop Med 2014;7:S224-7.

7. Strobel GA, Daisy B. Bioprospecting for microbial endophytes and their natural products. Microbiol Mol Biol Rev 2003b;67:491-502.

8. Bhagobaty RK, Joshi SR. Metabolite profiling of endophytic fungal isolates of five ethno-pharmacologically important plants of Meghalaya, India. J Metabol Syst Biol 2011;2:20-31.

9. Kaewpongumpai S, Poeaim S, Vanijajiva O. Sequencerelated amplified polymorphism (SRAP) analysis for studying genetic characterization of Bouea macrophylla. Biodiversitas 2016;17:539-43.

10. Rajan NS, Bhat R, Karim AA. Preliminary studies on the evaluation of nutritional composition of unripe and ripe 'Kundang' fruit (Bouea macrophylla Griffith). Intl Food Res J 2014;21:985-90.

11. Rajan NS, Bhat R. Antioxidant compounds and antioxidant activities in unripe and ripe kundang fruits (Bouea macrophylla Griffith). Fruits 2016;71:41-7.

12. Petrini O. Taxonomy of endophytic fungi of aerial plant tissues. In: Fokkena NJ, Van Den HJ, editors. Microbiology of the Phyllosphere. Cambridge: Cambridge University Press; 1986. p. 175-87.

13. Hiraishi A, Kamagata Y, Nakamura K. Polymerase chain reaction amplification and restriction fragment length polymorphism analysis of 16S rRNA genes from methanogenes. J Ferment Bioeng 1995;79:523-9.

14. Kumala S, Yuliani KD, Simanjuntak P. Antimicrobial activity of secondary metabolites produced by endophytic fungi isolated from stem of Jati tree (Tectona grandis L.F). Intl J Pharm Sci Res 2015;6:2349-53.

15. Yang Z, Zhang X, Duan D, Song Z, Yang M, Li S. Modified TLC bioautographic method for screening acetylcholinesterase inhibitors from plant extracts. J Sep Sci 2009;32:3257-9.

16. Simoes-Pires CA, Hmicha B, Marston A, Hostettman K. A TLC bioautographic method for the detection of $\alpha$ - and $\beta$-glucosidase inhibitors in plant extracts. Phytochem Anal 2009;20:511-5.

17. Perumal S, Pillai S, Cai LW, Mahmud R, Ramanathan S. Determination of minimum inhibitory concentration of Euphorbia hirta (L.) extracts by tetrazolium microplate Assay. J Nat Prod 2012;5:68-76.

18. Lee SY, Mediani A, Ashikin NA, Azliana AB, Abas F. Antioxidant and $\alpha$-glucosidase inhibitory activities of the leaf and stem of selected traditional medicinal plants. Intl Food Res J 2014;21:165-72.

19. Shahverdi AR, Abdolpour F, Monsef-Esfahani HR, Farsam H. A TLC bioautographic assay for the detection of nitrofurantoin resistance reversal compound. J Chromatogr B Analyt Technol Biomed Life Sci 2007;850:528-30

20. Bag A, Chattopadhyay RR. Evaluation of synergistic antibacterial and antioxidant efficacy of essential oils of spices and herbs in combination. PLoS One 2015. Available from: https://www.doi. org/10.1371/journal.pone.0131321. [Last accessed on 2017 Oct 16].

21. Marston A, Kissling J, Hostettman KA. A rapid TLC bioautographic method for the detection of acetylcholinesterase and butyrylcholinesterase inhibitors in plants. Phytochem Anal 2002;13:51-4.

22. Dewanjee S, Gangopadhyay M, Bhattacharyaa N, Khanra R, Dua TK. Bioautography and its scope in the field of natural product chemistry. J Pharm Anal 2015;5:75-84.

23. Pandey S, Sree A, Dash SS, Sethi DP. A novel method for screening beta-glucosidase inhibitors. BMC Microbiol 2013;13:55. Available from: http://www.biomedcentral.com/1471-2180/13/55. [Last accessed on 2017 Oct 16].

24. Mehta A, Zitzmann N, Rudd PM, Block TM, Dwek RA. $\alpha$-Glucosidase inhibitors as potential broad-based anti-viral agents. FEBS Lett 1998;430:17-22.

25. Silva MT, Simas SM, Batista TG, Cardarelli P, Tomassini TC. Studies on antimicrobial activity, in vitro, of Physalis angulata L. (Solanaceae) fraction and physalin B bringing out the importance of assay determination. Mem Inst Oswaldo Cruz 2005;100:779-82.

26. Pessini GL, Filho BP, Nakamura CV, Cortez DA. Antibacterial 
activity of extracts and neolignans from Piper regnellii (Miq.) C. DC. var. Pallescens (C. DC.) Yunck. Mem Inst Oswaldo Cruz 2003;98:1115-20.

27. Kumar S, Pandey AK. Medicinal attributes of Solanum xanthocarpum fruit consumed by several tribal communities as food: An in vitro antioxidant, anticancer and anti HIV perspective. BMC Comp Alt Med 2014;14:112-9.

28. Akpuaka A, Ekwenchi MM, Dashak DA, Dildar A. Biological activities of characterized isolates of $n$-hexane extract of Azadirachta indica A. Juss (Neem) leaves. N Y Sci J 2013;6:119-24.

29. Sharma D, Pramanik A, Agrawal PK. Evaluation of bioactive secondary metabolites from endophytic fungus Pestalotiopsis neglecta BAB-5510 isolated from leaves of Cupressus torulosa D. Don. 3 Biotech 2016;6:210-4.

30. Belakhdar G, Benjouad A, Abdennebi EH. Determination of some bioactive chemical constituents from Thesium humile Vahl. J Mater Environ Sci 2015;6:2778-83.

31. Nandhini US, Sangareshwari S, Lata K. Gas chromatography-mass spectrometry analysis of bioactive constituents from the marine streptomyces. Asian J Pharm Clin Res 2015;8:244-6.

32. Muthusamy K, Gopal V, Sivanandham V. GC-MS analysis of bioactive components of karisalaikarpa chooranam-a siddha poly herbal formulation. Intl J Phytopharm 2015;6:131-6.

How to cite this article:

Anindyawati T, Praptiwi P. A study of endophytic fungi Neofusicoccum ribis from Gandaria (Bouea macrophylla Griffith) as enzyme inhibitor, antibacterial, and antioxidant. J App Biol Biotech. 2019;7(01):48-53. DOI: $10.7324 / J A B B .2019 .70109$ 